\title{
La otra Revolución *
}

JAVIER DEL HOYO **

Resulta muy satisfactorio que, con motivo del II centenario de la Revolución Francesa, se hayan organizado estas Jornadas sobre "Revolución y revoluciones en el mundo antiguo". Primero porque entenderemos que la Revolución Francesa, ese acontecimiento que dio paso al mundo contemporáneo, no ha sido la única que se ha llevado a cabo en la Historia, y segundo porque nos dará pie para observar otros modos y maneras de Revolución.

En primer lugar, debiéramos de anotar qué entendemos por Revolución. El DRAE " lo define como "cambio violento en las instituciones políticas de una nación", pero también en sentido figurado "mudanza o nueva forma en el estado o gobierno de las cosas". Etimológicamente procede del latín revolutio, que significa el paso de una posición o estado de cosas a otro. Se utilizó primeramente en el campo de la astronomía para indicar el circuito que traza un astro para volver al punto de partida. De ahí pasó al léxico político, conservando en un principio un sentido próximo al astronómico; parece, en efecto, que el primer uso en el campo político tuvo lugar en 1660 para designar la "vuelta" a un estado de cosas precedente: la restauración de la monarquia inglesa después de la rebelión puritana y la dictadura de Cromwell ${ }^{2}$.

* Este articulo recoge básicamente la conferencia que, con el mismo titulo, fue pronunciada en Pamplona el 14 de septiembre de 1989 con motivo de unas "Jornadas sobre revolución y revoluciones en el mundo antiguo". De ahi su estilo directo y, en cierto modo, coloquial.

* Departamento de Filología clásica. Universidad Autónoma. Madrid.

' Diccionario de la Real Academia de la Lengua, 20. ed. Madrid, 1984, s. v.

2 Véase Gran Enciclopedia Rialp, t. XX, Madrid, 1974, pág. 226. 
Ahora bien, esta "vuelta" puede hacerse de un modo violento, tal como hemos visto recientemente reprimir a los estudiantes chinos en Tienan-men ${ }^{3}$, o a los rumanos en Timisoara y Bucarest ${ }^{4}$, o de un modo más pacífico, a lo Gandhi o Luther King, líderes asesinados en 1948 y 1968 respectivamente ${ }^{5}$. Distinguimos, pues, ya desde este momento revolución de revuelta, rebelión, pronunciamiento, golpe de estado, reforma social, etc.

El mundo antiguo ha asistido igualmente a revueltas de diversa indole ${ }^{6}$ : políticas, sociales, como la de esclavos protagonizada por Espartaco en el año 71 a.C., etc. Todas ellas han tenido y siguen teniendo las mismas características:

- un caldo de cultivo, es decir, una situación injusta que reclama una vuelta,

- unos hombres que la llevan a cabo,

- un mensaje que representa la idea-fuerza, que es motor de los protagonistas de la Revolución y que a su vez agrega nuevos nombres de día en día a la causa revolucionaria.

Por decirlo con palabras de Daniel Rops, «una situación revolucionaria, una doctrina revolucionaria y un personal revolucionario " ?.

Sin una de estas tres causas es difícil que pueda existir Revolución 0 , al menos, ésta no será duradera. Será más bien una rebelión. Pensemos en Revoluciones de nuestro siglo como la rusa o la islámica. Sin un desorden social, sin unos líderes que aglutinaran como Lenin o Jomeini,

${ }^{3}$ Revueltas de primeros de mayo de 1989 , en las que la policia reprimió a los estudiantes en la plaza de Tienan-men, en Pekín, con un balance de varios miles de muertos.

${ }^{4}$ Levantamientos producidos en las dos ciudades citadas entre el 18 y el 24 de diciembre de 1989, que terminaron con la muerte del dictador $N$. Ceaucescu y su esposa.

5 Véanse al respecto las excelentes monografias de LOUIS FISCHER, Gandhi, Barcelona, Plaza \& Janés, 1983, inspiradora de la pelicula de R. Attenborough del mismo título, y la de Minestrini, Walter, Martin Luther King, rebelde por amor, Bilbao, Mensajero, 1979.

${ }^{6}$ La bibliografía sobre el tema es extensisima y no podemos aquí sino seleccionar lo más representativo. Se ha convertido ya en una obra clásica en este tema la de SYME, $R$., The Roman Revolution, Oxford, 1939 (trad. de A. Blanco Freijeiro, Taurus, Madrid 1989). Muy interesantes asimismo pueden resultar el capitulo de Finley, M. I., "Revolution in Antiquity", en la obra de PORTER, R., y TEICH, M. (eds.), Revolution in History, Cambridge, 1986; FERguson. Utopia in Ancient World, Londres, 1974; Brunt, P. A., Conflictos sociales en la República romana, Buenos Aires, 1974; LINTOTT, A. W., Violence in Republican Rome, Oxford, 1970; MacMullen, R., Enemies of the roman Order, Cambridge -Mass.-, 1967; Guarino, A., La rivoluzione della plebe, Nápoles, 1975.

${ }^{7}$ La lglesia de los apostoles y de los mártires, Luis de Caralt, Barcelona, 1955, pág. 134. 
sin un ideario de salvación, redención, promesas de un futuro paraíso, etc., hubiera sido imposible la persistencia y triunfo de su Revolución.

En la Antigüedad hallamos un acontecimiento que hizo girar el curso de la Historia. Lo he denominado "La otra Revolución» porque de forma pacífica, sin armas ni ejércitos, dio la vuelta a un orden de cosas establecido. Sin otra agresividad que la de un discurso pronunciado en la falda de un monte - cuyo análisis desde un punto de vista estratégico es un auténtico escándalo y augura un ruidoso fracaso-, con un mensaje y unos hombres dispuestos a defender su doctrina con su vida ${ }^{8}$, hicieron saltar por los aires una sociedad anémica que no ofrecía ya resortes vitales a sus ciudadanos ${ }^{9}$. Nos referimos a la aparición y progresiva difusión, hasta su definitiva implantación oficial en 387 por el emperador Teodosio, del cristianismo.

Quisiera adelantar, antes de seguir, que evidentemente el tema es tan sumamente amplio que ni siquiera me dará tiempo ni tendré espacio para esbozarlo, para apuntarlo. Vamos a asomarnos a él como de puntillas, con una audacia que a más de uno le sorprenderá y con una visión tan general que de cada punto concreto podría salir una monografía de gran volumen. La bibliografía utilizada y que vamos remitiendo en notas no es ni siquiera la fundamental, puesto que sólo en referencias bibliográficas acerca de los temas que iremos enumerando podrian llenarse varios volúmenes. No será tampoco "arma arrojadiza contra paganos", sino ensayo iniciador de diálogos.

La otra Revolución porque constituyó una auténtica ruptura en la forma de pensar y vivir de la Antigüedad, pero también porque lo fue en el mensaje mismo y en el modo de llevarlo a cabo. Podríamos decir que fue una Revolución no sólo de fondo, sino también de forma. La ausencia de elementos típicamente revolucionarios es bien patente como ya hemos visto. Quizá lo paradójico del caso es que si bien los primeros cristianos están muy lejos de ser unos (por utilizar terminologia actual) guerrilleros, tampoco son pacifistas.

Los primeros cristianos se alejan abiertamente de los cínicos, de aquel pacifismo del que Diógenes fue un buen representante. Constituyen

${ }^{8}$ Véase el interesante articulo de J. Sánchez Lasso de la Vega, "Héroe griego y mártir cristiano", en Ideales de la formación griega (Rialp, Madrid 1966), págs. 181-272, publicado anteriormente por la Universidad de La Laguna en 1962.

${ }^{9}$ Marrou, H. I., en ¿Decadencia romana o antigüedad tardia? Siglos II-VI, Rialp, Madrid, 1980, ha expuesto magistralmente el advenimiento de una sociedad cristiana por el agotamiento de una sociedad imperial que no alimentaba vitalmente a sus ciudadanos. 
en todas sus posturas realmente un tertium genus ${ }^{10}$. Su postura representa siempre un punto de equilibrio, sin inclinarse a los rigorismos propios de las épocas de transición, crisis o inestabilidad. No se entregan a los placeres de la carne, pero tampoco condenan el matrimonio como maniqueos o montanistas ${ }^{11}$; no abusan de la mujer, pero tampoco la desprecian como los esenios ${ }^{12}$; no codician las riquezas, pero tampoco las desestiman, pues su pobreza consiste en el desasimiento de los bienes de la tierra una vez valorada la posesión personal de los mismos; no disputan por los grandes cargos públicos, pero tampoco los menosprecian, poniendo al servicio de la sociedad y de la comunidad en general sus talentos, profesión, etc. y ocupando todo tipo de cargos, oficios y profesiones ${ }^{13}$. No rinden culto al emperador ${ }^{14}$, pero tampoco rechazan su persona. Tertuliano, por ejemplo, en el Apologeticum ${ }^{15}$ desarrolla ampliamente la idea de orar por los emperadores en sustitución del sacrificio por ellos $e$ insiste en que esta oración está dirigida al Dios del cielo, a ese Dios que ha dado al emperador su imperio. Su vida y su doctrina, lejos de identificarse con una clase social, se enquista en todas las estructuras de la vida social y así observamos a esclavos como el papa Calixto, y a patricias como santa Cecilia junto a la madre del emperador Constantino, santa Elena ${ }^{16}$.

El cristianismo no rechazó ninguna estructura de la Antigüedad «por el hecho mismo de ser pagana" ${ }^{17}$, antes bien adoptó todo aquello que

10 Término acuñado por San Agustín con el que se designa al cristiano como un nuevo tipo de hombre que se separa tanto del hombre clásico grecolatino como del hebreo. rigorista.

$"$ Las obras de Tertuliano en su etapa montanista son buen reflejo de esta actitud

12 Trabajo fundamental a este respecto puede resultar el de PhILONENKo, M., «Essénisme et misogynie", en Académie des inscriptions \& Belles Lettres, abril-junio 1982 , págs. 339-353.

13 "Asistian, como los demás ciudadanos, al foro, al mercado, las oficinas, a la tienda, a las plazas públicas. Eran marineros, soldados, agricultores y comerciantes" (TERTULIANO, Apologeticum XLII). HAMmAN, Adalbert, ha descrito varios de estos oficios y profesiones en su obra La vida cotidiana de los primeros cristianos, Madrid, Palabra, 1985, págs. 5361.

En los índices de DIEHL, Inscriptiones latinae christianae, vol. III, podemos observar cómo las profesiones ocupadas por los cristianos, y registradas en la epigrafia, son similares a las desempeñadas por los paganos.

${ }^{14}$ SoRDi, Marta, ha estudiado en Los cristianos y el Imperio romano, Madrid, Encuentro, 1988, la problemática y la relación de los cristianos con el culto imperial.

1532,2 ss.

${ }^{16}$ Como ha visto KLeberg, T., Hôtels, restaurants et cabarets dans l'Antiquité romaine, Upsala, 1957, págs. 111-112, Santa Elena fue "la más célebre de las chicas de taberna".

17 El término 'pagano' procede de pagus, aldea, villorrio. En un primer momento el cristianismo se difunde por las grandes ciudades del Imperio. Sólo más tarde llegará a los 
podía servirle ${ }^{18}$. El cristianismo no condenó, salvo lo que se oponía directamente al concepto de hombre, vida, derecho natural...

El monacato cristiano, por ejemplo, no es original en su estructura. Encontramos monjes en otros círculos religiosos como el budismo o el judaísmo y en otros dominios culturales como el egipcio o el pitagorismo griego. Este último es digno de mención por su larga pervivencia y por algunos de los elementos que lo componen: "Sólo se podia ingresar en la comunidad después de superar un riguroso examen de admisión, una primera prueba que duraba tres años y una segunda que duraba cinco. Al principio de este segundo 'noviciado', renunciaba el candidato a sus propios bienes en favor de la comunidad. A lo largo de todos los años de probación, debian guardar los novicios ininterrumpido silencio [...]. Practicaban también la obediencia al maestro y escuchaban sus enseñanzas con gran devoción. Desde el día de su iniciación llevaban los pitagóricos un vestido distintivo y observaban un horario regular. Una de sus prácticas más relevantes era el examen de conciencia diario. Comían en comunidad de acuerdo con un régimen dietético estrictamente vegetariano; antes y después de las comidas rezaban y mientras tomaban el alimento escuchaban la lectura que hacia el más joven" ${ }^{19}$.

En la Vida de Apolonio de Tiana leemos que Apolonio era pitagórico porque "despreciaba el vino, la carne y los vestidos de lana; vestía de lino y andaba descalzo, se dejaba crecer el pelo, llevaba los ojos bajos y habia prometido castidad perpetua» ${ }^{20}$. La originalidad del monacato cristiano, sin embargo, estriba esencialmente en el motivo por el que nace. Quizá por ello todavía hoy perdura. En efecto, para aquellos hombres y mujeres que se retiraban al desierto como monjes, el motivo no era tanto la huida del mundo, ni siquiera la búsqueda de la perfección personal, como la imitación de Cristo y el deseo de entregar la vida por Él. Pensemos que el movimiento de anacoretas y eremitas surge a partir del Edicto de Milán, en el 313 , al terminar la era martirial. Aquellos primeros cristianos, que habían entendido el martirio como una forma de corresponder a Cristo entregando su vida, encuentran -en una época sin persecuciones- en esta vida retirada los mismos ideales que en el martirio.

campos; por ello 'pagano', en un principio 'habitante de un pagus', pasa a significar 'no cristiano'. Cf. CoRominAS, J., Diccionario critico etimológico castellano e hispanoamericano, Gredos, Madrid 1981, tomo IV, pág. 338.

${ }_{18}$ Pensemos en la reutilización de costumbres, fiestas, estructuras, como la administrativa de Diocleciano en diócesis, etc.

${ }^{19}$ Colombas, Garcia, El monacato primitivo, I, Madrid, BAC, 1974, pág. 16.

${ }^{20}$ Filostrato, Vita Apollonii, VI, 11. 
Revolución del cristianismo en la idea de templo. Mientras para los griegos era el espacio acotado (témenos) donde residia la estatua del dios/a, pero donde no entraban sino los sacerdotes (análogamente al sancta sanctorum del templo de Jerusalén para el judaísmo), para los cristianos el templo, cuyo nombre es sustituido en un principio por el de basilica ${ }^{21}$ y más tarde por el de ecclesia, según podemos observar en los documentos epigráficos de los primeros siglos ${ }^{22}$, es el lugar donde el fiel se relaciona con su Dios, donde puede hablar con Él cara a cara ${ }^{23}$, donde asiste a la fracción del pan (realizada en los primeros tiempos en las $\operatorname{casas}^{24}$ ), y donde le come. Esta misma idea no es sólo revolucionaria ${ }^{25}$, sino un escándalo. Para los griegos los dioses están situados en el Olimpo, son impasibles y totalmente independientes de la vida del hombre. El Dios de los cristianos -en cambio- es completamente personal, se le acostumbra a llamar $\operatorname{Pater}^{26}$ y no es «apático"

${ }^{21}$ El edificio de culto que se extiende por todo el mundo romano a partir del 313 es lo que los arqueólogos llaman «basílicas" (véase el estudio de MARROU, H. I., en obra citada, págs. 109-116).

22 Véase DiEHL, obra citada.

${ }^{23}$ Los cristianos primitivos extendieron el término parrhesia, (ya existente en griego clásico, aplicado al privilegio de poder tomar la palabra en la asamblea del pueblo, de que gozaban los ciudadanos libres por oposición a los esclavos), a la familiaridad o libertad con que el bautizado hablaba con su Dios. En la Vita Euthymii, 7, leemos: "El venerable Eutimio aventajaba [a Teoctisto] por la simplicidad de carácter [...]. Había recibido también la gracia del Espíritu Santo [...]. Por eso su libertad de lenguaje (parrhesia) para con Dios crecía día a dia."

Sobre este concepto puede verse bibliografía en El monacato primitivo, de COLOMBAS, García, Madrid, BAC, 1975, t. II, pág. 296, nota 77.

${ }_{24}$ Sobre la organización de la Eucaristía en los primeros momentos, véase La asamblea cristiana en tiempo de los apóstoles, de ChIRAT, Henri, Madrid, Studium, 1968, págs. 121-159.

${ }_{25}$ Sí es cierto que en algunos misterios, como los dionisíacos, habia todo un ritual de muerte y resurrección, en que los iniciados decian comer al dios y beber el vino que les uniria a la divinidad y les proporcionaría la inmortalidad, pero este tipo de ceremonias no tiene ningún tipo de comparación con el misterio de la Eucaristía, ni por el género de personas que los practican, ni por los efectos posteriores a la ingesta de la carne de Cristo. V. especialmente sobre este punto la tesis doctoral de Garcia Sanz, O., Baco en Hispania. Economia y religión a través de las fuentes epigráficas, arqueológicas y literarias (UCM, Madrid 1990, tesis doctorales 233/90), págs. 51-61. Para las relaciones de los cultos dionisíacos con el cristianismo, v. págs. 226-238.

Asimismo, sobre este mismo punto pueden verse algunos de los trabajos del Coloquio de Poitiers (13-14 mayo 1983) sobre Mort et fécondité dans les mythologies, París, Belles Lettres, 1986.

${ }_{26}$ La paternidad de Dios es un concepto que no ha sido desarrollado por ninguna religión, cultura ni mentalidad filosófica tanto como por el cristianismo. El paganismo invoca a "Marduk, señor, gran rey de los dioses, que sostiene los ejes del cielo y de la tierra", 0 levanta los ojos hacia "Sin, el que alumbra lo grande y lo pequeño, y se adorna con los amplios cuernos, y se viste de gloria", o intenta atraerse el favor de "Nabú, escribano de 
como el de los griegos, sino «simpático»; un Dios que, aunque ontológicamente no puede sufrir, si psicológicamente ${ }^{27}$.

Quizá lo esencial del cristianismo fue pretender cambiar la estructura no directamente, sino intentando transformar a cada uno de los que componían esa estructura; a todos y cada uno, libres y esclavos, hombres y mujeres, judios, griegos y romanos. Como muestra de ello baste la carta de san Pablo a Filemón, en que le pide que acoja de nuevo a su esclavo Onésimo. No hace una abolición formal de la esclavitud, que de hecho siguió existiendo, sino que eleva la condición del hombre haciendo iguales al libre y al esclavo. "Ya no hay libre ni esclavo", dirá en Gál 3, 28.

El cambio de mentalidad es notable. Del «todo es lícito con los esclavos» de Séneca ${ }^{28}$ se pasa al "los que están bajo el yugo de la servidumbre tengan a sus amos por acreedores de todo honor [...]. Los que tengan amos fieles no los desprecien por ser humanos" de su contemporáneo san Pablo (1 $\operatorname{Tim} 6,1$ ss.).

La Iglesia plasmará en leyes los cambios operados en la vida: en el derecho eclesiástico, el papa Calixto - antiguo esclavo- autoriza en sus Constituciones Apostólicas (VII, 32) contra las costumbres romanas, el matrimonio de libres con esclavos o libertos, asi como que en los cementerios cristianos no se haga mención de la condición de esclavos en las inscripciones funerarias, que entre los no cristianos era obligatoria, aunque sabemos que muchas veces se omitian por evitar la humillación que ello suponía ${ }^{29}$.

los dioses que dispone del gran cálamo y posee la tabla de los divinos destinos", mientras que el cristiano dice simplemente "Padre nuestro..." $(M t 6,9)$. Un ensayo reciente de José M. ${ }^{a}$ Cabodevilla sobre el Discurso del padrenuestro, Madrid, BAC, 1986, hace hincapié en la primera parte del libro (págs. 27-166) en esta idea.

Digna de mención, asimismo, es la expresión Abba con que Jesucristo se dirigió a su Padre $(M c 14,36)$, que era el término con que el niño judio se dirigia a su padre. Su significado, algo impreciso y siempre con un sentido muy familiar, es algo así como "papaiton.

27 Un gran conocedor del pensamiento clásico, como fue ORIGENES, no dudó en exclamar: «El Padre mismo no es impasible; si se le pide, Él tiene piedad y compasión; sufre de una pasión de amor" (Homil. in Ezech., 6, 6). Henri de Lubac hizo un bello comentario de este pasaje: "Texto asombroso. Origenes conocia las susceptibilidades de los filósofos en esta materia. Él mismo enuncia en otros pasajes el dogma de la impasibilidad divina [...]. Pero lanza la expresión paradójica [... . Afirma que en su amor al hombre el impasible ha sufrido una pasión de misericordia", Histoire et Esprit. L'intelligence de l'Ecriture d'apres Origène, París, 1950, págs. 241-243.

${ }^{28}$ De clementia. I, 18.

${ }^{29}$ Véase a este propósito la obra de MANGas, J., Esclavos y libertos de la España romana, Salamanca, 1975, y de WALLON, H., Histoire de l'esclavage dans l'Antiquité, III, vol. I, París, 1847; II-III, 1879, y para la relación de los esclavos con el cristianismo, v. 
Como ha visto $\mathrm{S}$. Kierkegaard, aquella Revolución triunfó porque "tuvo en su base un gran espíritu de sacrificio» ${ }^{30}$, espíritu que puede detectarse en cualquier página de la literatura paleocristiana.

El cristianismo supone una Revolución en la forma de concebir al hombre. Eleva la condición del ser humano, le confiere una dignidad perdida. Pensemos por un momento en la mujer. Frente a sentencias como la que Tito Livio pone en labios de Catón: "Soltad las riendas a esa naturaleza incontrolable (impotenti naturae), a ese animal indómito (indomito animali) y esperad en vano que ellas mismas pongan límite a su libertinaje, si no lo hacéis vosotros" ${ }^{31}$, predica san Pablo su "ya no hay hombre ni mujer, todos vosotros uno sois en Cristo Jesús" (Gál 3, 28). Las frases denigratorias contra la mujer en la Antigüedad son numerosísimas. Aparece como "fuente de todos los males" ${ }^{32}$; "de juicio poco fiable» ${ }^{33}$; «incapaces de guardar fidelidad" ${ }^{34}$ y de "mantener su palabra» ${ }^{35}$. Séneca escribió que "algunos son tan estúpidos que creen poder ser ofendidos por una mujer ${ }^{36}$.

La mujer constituye uno de los sectores de población más beneficiados por el cristianismo ${ }^{37}$. Pone de manifiesto la excelencia de la virginidad ${ }^{38}$, pero protege asimismo el matrimonio y favorece ostensible-

especialmente la obra de ScHMid, Jöel, Vie et mort des esclaves dans la Rome antique, Paris 1973

${ }^{30}$ Ejercitación del cristianismo, Madrid, 1961, pág. 35.

${ }^{31}$ Ab urbe condita, XXXIV, 3.

${ }^{32}$ SENECA, Fedra, 559.

${ }^{33}$ Mulier est; errat (SÉnECA, De ira II, 30, 1).

34 JuVENAL, Sátiras, VI.

${ }^{35}$ Catulo, Carmina, LXX.

${ }^{36}$ De consolatione sapientiae, $14,1$.

${ }^{37}$ Acerca del misoginismo en la Antigüedad, entre romanos, griegos y judios principalmente, tanto en la literatura como en los aspectos jurídicos, puede verse abundantisima bibliografia. Resulta interesante, aunque se va quedando atrasado, el articulo de GARRIDO, Elisa, "Problemática del estudio de la mujer en el mundo antiguo. Aportación bibliográfica", en "La mujer en el mundo antiguo", Actas de las $V$ Jornadas de Investigación Interdisciplinaria, Madrid, Univ. Autónoma de Madrid, 1986, págs. 29-65. Se trata de una útil recopilación bibliográfica en que las distintas referencias quedan distribuidas por temas.

${ }^{38}$ Cf. 1 Cor 7, 32-34, donde san Pablo expresa la idea de la virginidad como superior al matrimonio. Los escritos de los santos Padres sobre las excelencias de la virginidad son numerosisimos y seria ocioso dar cuenta detallada de todos ellos.

Entre los romanos - por el contrario-, a pesar de la existencia de las Vestales, la virginidad no estaba suficientemente considerada. Los médicos opinaron a favor y en contra de la virginidad en relación con su salud. El médico griego Soranos, que se formó en Alejandria y después se instaló en Roma en época de Trajano y Adriano, recogió en su Gynaeceia las opiniones sobre el tema. Es interesante a este respecto la lectura del capitulo IV de la obra de Gourevitch, Danielle, Le mal d'être femme. Paris, Belles Lettres, 1984, págs. 105-111. 
mente a las viudas. Si condena el divorcio, el adulterio, la violación, fornicación, prostitución, incesto, aborto, etc. ${ }^{39}$, no es tanto por situarse «en contra de", como por estar "a favor de» la condición femenina (y no tanto por ser mujer como ser humano), para proteger la estructura conyugal.

La exhortación a la castidad se reveló eficaz allí donde las medidas legislativas de los emperadores fracasaban para reconstruir los fundamentos de la moral sexual y familiar ${ }^{40}$; la crisis del matrimonio y de la natalidad ${ }^{41}$ quedó resuelta de golpe (pensemos que mientras la madre de los Gracos se enorgullecía de sus 12 hijos, al comienzo del siglo II se alababan como excepcionales los padres que tenían tres). Se eludía el matrimonio porque la orbitas, el celibato, tenía todas las ventajas, la principal era asegurar al rico una fiel clientela de herederos en expectativa.

Otro tanto podria decirse de la consideración nueva que se hace del niño. En la Ley de las XII tablas se leía: "A los niños débiles y contrahechos los ahogamos [...]. El niño no es hombre todavia" ${ }^{42}$. Luciano, sarcástico observador de los cristianos, describe el lugar tan alto que entre los cristianos se reserva a las viudas y los niños huérfanos ${ }^{43}$. Muchos de estos niños se libraban de la muerte por medio de la esclavitud y la prostitución. Tertuliano reprocha violentamente a los paganos la exposición de los hijos no deseados ${ }^{44}$. Para el cristiano el niño es ya un hombre, es decir, un ser humano y - como tal- digno de todo respeto y dotado de plenos derechos. "Él (Jc.), llamando a Si a un niño, lo puso en medio de ellos y dijo: "En verdad os digo que si no os hacéis como niños no entraréis en el Reino de los Cielos."” (Mt 18, 2). En la Didascalia (XVII) encontramos este párrafo, reflejo de una práctica habitual:

${ }^{39} \mathrm{Cf} .1$ Cor $6,9-10$.

40 Augusto promovio mediante las leyes lulia de maritandis ordinibus (cf. ROTONDI, Leges publicae populi romani. Hildesheim, 1966, págs. 443-445) y Lex Papia Pappaea nuptialis (cf. ibidem, págs. 457-462), promulgada ésta el 9 d.C. la protección del matrimonio y de la natalidad. La base de estas leyes estuvo posiblemente en la necesidad que encontraba Augusto de tener disponible en todo momento una gran población para engrosar el ejército, que iba a mantener incólumes las fronteras del Imperio (véase CASTILLO, Arcadio del, La emancipación de la mujer romana en el siglo / d.C.. Granada, 1976, pág. 15, y TREGGIARI, S., "Libertine Ladies", en Classical World LXIV, 1971, pág. 198).

${ }^{41}$ Sobre la relajación de costumbres en Roma y en concreto el tratamiento del adulterio, divorcio, aborto, anticoncepción e infanticidio, vease CASTILLO, Arcadio del, obra citada, págs, 81-122.

${ }^{42}$ Sobre el niño en Roma, véase la elaborada monografia de Neroudau, J. P.. Etre enfant à Rome, Paris, Belles Lettres, 1986.

${ }^{43}$ Peregrino, 12.

id Apologeticum IX. 
"Si un cristiano se encuentra huérfano, niño o niña, será hermoso que uno de los hermanos que no tiene hijos tome por hijo a tal niño $y$, si tiene ya un hijo, que tome a la niña y se la dé por esposa a su debido tiempo para coronar en servicio de Dios." Se trataba de abrir los hogares para ofrecer una familia al huérfano, situarlo en la vida mediante el ofrecimiento de un trabajo, facilitar su matrimonio.

Revolución en el pensamiento ${ }^{45}$ porque, si bien toma aspectos del pensamiento clásico, especialmente del platonismo, los adapta no obstante a sus formas sin renunciar a su esencia. Cambios fundamentales que introduce el cristianismo son:

- El concepto lineal de la Historia frente al circular de la Antigüedad clásica, donde se insiste en la repetición del acontecer histórico. En esta idea circular, con la sucesión de las distintas edades de oro, plata, bronce y hierro, se encuadra el pensamiento virgiliano ${ }^{46}$ y de Ovidio, por ejemplo. Por otra parte, el hecho de que Cristo nazca en un momento concreto del acontecer histórico, hace que pasado y futuro giren en torno suyo.

- El Cosmos ha sido creado por Dios y tiene un origen y un fin, mientras que en los planteamientos clásicos el Cosmos tiene un origen, pero no un fin.

- Monoteísmo cristiano frente al panteón clásico.

- Dios adquirió forma humana para redimir del pecado al mundo. Se desvía totalmente del concepto del dios de los clásicos, para quienes los dioses, de forma humana, eran víctimas de las mismas pasiones que el hombre, que exacerbaban en grado sumo.

- Espíritu universal y "católico". El cristianismo se dirige a todos los pueblos y gentes sin considerar clase social, sexo, etnia, etc. Ante Dios todos tienen los mismos derechos.

${ }^{45}$ N. Cochrane, Charles, en Cristianismo y cultura clásica. Fondo de Cultura Económica, Méjico, 1983, ha sabido plasmar muchas de estas similitudes y diferencias. Es notable el capítulo VI, “Quid Athenae Hierosolymis?”, págs. 213-258.

${ }_{46}$ Parece evidente que al acercarse el siglo I de nuestra era, el cuerpo social del Imperio romano presentaba ciertas fisuras y heridas que el pueblo esperaba que fuesen restañadas. Augusto supo aprovechar políticamente esta situación moral y social. Virgilio al evocar en su Egloga IV (redactada el año 40 a.J.) el fin de la edad de hierro y la entrada del mundo en la edad de oro, parecia designar al ser providencial en quien se encarnaria la esperanza humana. CARCOPINO, J., en su estudio sobre el tema, publicado en París en 1930, Virgile et le mystère de la IV Eglogue, penetra en el doble plano del poema:

a) nacimiento del hijo de un alto personaje,

b) elucubración por la que pasa "un mensaje inmortal de la esperanza humana".

Augusto puso empeño en rehacer el orden social del Imperio, pero, como observó D. Rops, «en todos los tiempos y en todos los países la sustitución de un instinto por una voluntad estatal es un signo total de decadencia” (obra citada, pág. 128). 
- Concepto de «libertad". Todo es conocido y dispuesto por Dios, pero el hombre puede elegir su camino. Se opone al determinismo clásico, según el cual el hombre nace con un destino marcado y no puede desprenderse de él, como vemos magistralmente expuesto en Edipo Rey, de Sófocles ${ }^{47}$.

- Se rechazan los sacrificios porque Jesucristo, con su muerte en la cruz, ha redimido al hombre, si bien -insistirá san Pablocada hombre debe completar en su carne lo que le falta a la Pasión de Cristo (cf. Col 1, 24).

- Dios es tan grande que el hombre es incapaz de imaginárselo y más de representarlo. Se rechaza, por ello, el culto a las imágenes en cuanto que se pueda creer que contienen algo de la esencia de Dios ${ }^{48}$. "No te harás escultura ni imagen alguna ni de lo que hay arriba en los cielos, ni de lo que hay abajo en la tierra, ni de lo que hay en las aguas debajo de la tierra" (Ex 20,4).

- Renovación del concepto de ocio y de fiesta. Reaprovecha algunas de las existentes dándoles un valor distinto (el 25 de diciembre, solsticio de invierno, celebraron los romanos las saturnalia y el mithraísmo, el nacimiento del Sol Invictus) y crea otras nuevas.

Culturalmente la entrada en escena del cristianismo en la Historia supone una ruptura con todo orden anterior. La predicación de las Bienaventuranzas y especialmente de la Cruz constituye, como bien argumentó Pablo, un "escándalo para los judios y locura para los gentiles, pero para los mismos que han sido llamados, judios y griegos, fuerza de Dios y sabiduría de Dios" (/ Cor 1, 23-24).

La consideración positiva de la "pobreza", por ejemplo, es un concepto nuevo en la Historia. Supone la entrada en vigor de nuevas categorías, la preferencia de la filosofía del "ser" sobre la del "tener». No es que en los siglos que comprenden lo que llamamos Historia Antigua no hubiera pobres, sino que su condición era despreciada. Incluso entre los judios se consideraba la riqueza como un signo de haber obtenido el favor de Dios. Mucho menos pensable aún era la idea de empobrecerse

47 Moeller, Charles, en Sabiduria griega y paradoja cristiana, Madrid, Encuentro, 1989, ha estudiado el problema del sufrimiento y la paradoja del "justo doliente" en la tragedia griega con gran acierto, págs. 119-164.

${ }_{48}$ En la obra de Gigon, Olof, La cultura antigua y el cristianismo, Madrid, Gredos, 1970. se hace una exposición muy buena de las diferencias marcadas entre los dos sistemas de pensamiento y acción que venimos confrontando, especialmente en su último capítulo, "Visión sistemática y de conjunto", págs. 201-258. 
voluntariamente repartiéndolo todo a los pobres para seguir a Alguien, en este caso Dios.

Con esta práctica de vender lo propio y ponerlo a disposición de la comunidad (cf. Hech 2, 45) nacen conceptos nuevos como comunidad de bienes, ayuda a pobres, etc. y cargos completamente nuevos como diáconos y diaconisas.

Revolución en conceptos como el de trabajo. La ociosidad se había oficializado en Roma. La costumbre de hacerse alimentar por el Estado fue en aumento; algunas fuentes indican que en el siglo ॥ d.C., sobre una población de 1.200 .000 personas, no habría más de 100.000 cabezas de familia que no llamasen a las ventanillas de la annona. Frente a ello la moral cristiana del trabajo (recordemos aquel "quien no quiera trabajar que no coma" de /I Tes 3,10 ) cortó de raíz la holgazaneria. El hecho de que Lenin recogiera palabra por palabra la exhortación paulina subraya bien a las claras su carácter revolucionario.

El cristianismo supone también una Revolución en lo que respecta a la idea de la "muerte». Mientras para el pagano es un fin ${ }^{49}$, para el cristiano es un principio. Los cristianos no hablaban de muerte, sino de tránsito, encuentro, venida, etc. ${ }^{50}$ Un estudio detenido de la epigrafía funeraria pagana ${ }^{51}$ y paleocristiana ${ }^{52}$ nos sitúa en perspectiva idónea para hacer esta observación. Los mismos "elogia", aun dentro de un estilo formular, presentan características completamente distintas ${ }^{53}$. Mientras los primeros hacen referencias constantes a la vida que se acaba de

49 Vease como obra básica la de PRIEUR, Jean, La mort dans l'antiquité romaine, París, 1986, que presenta cuatro capítulos básicos: los ritos, los monumentos, el más allá y el simbolismo funerario.

Pueden servir para un primer acercamiento las de ARIES, Philippe, L'homme devant la mort, París, Du Séuil, 1977; la obra preparada bajo la dirección de GNOLI, G., y VERNANT, J. P., La mort, les morts dans les sociétés anciennes, París, Ed. de la Maison des Sciences de l'Homme, 1982; Morin, E., Lhomme et la mort. Paris, Du Séuil, 1976, y la de TOYNBEE, J. M. C., Death and Burial in the Roman World, Londres, Thames and Hudson, 1971.

50 Resulta revelador en este punto leer los discursos de los santos Padres con motivo de la muerte de un cristiano, de un familiar, etc. Existe una recopilación de homilias funerales hecha por Cayuela, Arturo, No llores más, Bilbao, Mensajero, 1932, que llega de San Basilio a San Ambrosio, aunque continúa con otras de autores medievales y modernos.

51 Fundamental en este punto es la obra de BRELICH, A., Aspetti della morte nelle iscrizioni sepolcrali dell'imperio romano, Budapest, 1937.

52 Véase la obra de Janssens, Jos, Vita e morte del cristiano negli epitaffi di Roma anteriori al sec. vil. Roma, Univ. Gregoriana, 1981.

${ }_{53}$ Véase nuestro estudio "Herencia e innovación en los elogia feminarum de la epigrafia hispano-cristiana", en Actas del I Simposio de Latín Cristiano, Salamanca, Univ. Pontif. Salamanca, 1990, págs. 321-333. 
abandonar, los otros - por el contrario- encaminan al difunto/a, a su alma, a la vida que van a encontrar. Las inscripciones cristianas, precisamente, son las únicas que hacen notar el día exacto de la defunción. En efecto, la muerte como paso para la vida, constituye un nuevo dies natalis. Por ello también se empezará a conmemorar como fiesta de los santos el día de su muerte, nacimiento a la vida eterna.

Por otra parte, el miedo a la muerte parece desaparecer en el ánimo de los cristianos. Basta leer las Actas de los mártires ${ }^{54}$, la Exhortación al martirio de Origenes ${ }^{55}$, o algunas obras de Tertuliano ${ }^{56}$ para convencerse de este hecho. Para este autor morir por Cristo no es sinónimo de aceptación indiferente del sufrimiento y de la paciencia estoica. Es la prueba más alta del valor y de la intrepidez. Es un combate en el sentido más pleno de la palabra. Tertuliano en su obra Ad martyras escoge sus imágenes más expresivas de los combates de la arena y de distintas fases de la vida militar. "No pretendo - dirá en el primer capítulo- exhibir ningún título especial para exhortaros a vosotros. Sin embargo, no son sólo los entrenadores y los presidentes de los espectáculos, sino también la gente inexperta y el público en general quienes animan de lejos a los más diestros gladiadores, y no es raro que las sugerencias de la multitud les hagan mucho bien».

En esta misma línea de pensamiento el cristianismo supuso una revolución en la manera de concebir el dolor, el sufrimiento, etc. El acta del martirio de Felicidad y Perpetua, por poner sólo un ejemplo entre otros muchos, es bien patente ${ }^{57}$.

Revolución en el sentido de cumplir con los deberes de ciudadano. san Pablo insistirá en que los cristianos pagan los impuestos a tiempo y la Carta a Diogneto dirá de los cristianos: "Obedecen las leyes establecidas; pero con su vida sobrepasan las leyes" (V, 10).

$Y$ toda esta Revolución, ¿que hombres la llevan a cabo? Hombres normales sin duda, sin ningún tipo de especialización. Eso hizo del cristianismo una religión universal, es decir "católica", para todos. A diferen-

${ }^{54}$ En castellano tenemos la edición bilingüe completa preparada por Daniel Ruiz Bueno en BAC, Madrid, 1975.

${ }^{55}$ Editada por KOETSCHAN, P., en Die griechischen christlichen Schrifsteller ( $=$ GCS) 2 Leipzig 1899, págs. 1-47.

${ }_{56}$ Exhortación a los mártires por ejemplo, opúsculo escrito a fines del siglo /1. Aparece editado y traducido en Actas de los mártires, Madrid, BAC, 1975, págs. 383-393.

${ }^{57}$ Actas de los mártires, Madrid, BAC, 1975, págs. 397-459. 
cia de los cultos mistéricos, del mitraísmo ${ }^{58}$ por ejemplo, que cobró fuerza en algunos puntos del Imperio, pero que requería unos períodos de iniciación ${ }^{58}$ bis , los cristianos, por decirlo con palabras de la Carta a Diogneto, fechada en el siglo II, «no se distinguen de los demás hombres ni por su tierra ni por su habla ni por sus costumbres, porque ni habitan ciudades exclusivamente suyas, ni hablan una lengua extraña, ni llevan un género de vida aparte de los demás [...], sino que, habitando ciudades griegas o bárbaras [...] y adaptándose en vestido, comida y demás género de vida a los usos y costumbres de cada país, dan muestras de un tenor peculiar de conducta, admirable y - por confesión de todos- sorprendente. Habitan sus propias patrias, pero como forasteros; toman parte en todo como ciudadanos y todo lo soportan como extranjeros. Toda tierra extraña es para ellos patria, y toda patria tierra extraña. Se casan como todos; como todos engendran hijos, pero no exponen a aquellos que les nacen. Ponen mesa en común, pero no lecho. Están en la carne, pero no viven según la carne. Se los desconoce y se los condena. Se los mata y en ello se les da la vida. Son pobres y enriquecen a muchos» ${ }^{59}$.

Esta adaptación a la vida cultural se muestra no sólo en el respeto y admiración por la cultura clásica, sino en su difusión. Parece ya tópico, aunque obligado, citar a san Agustín y su entusiasmo por la Eneida en particular y por la literatura latina en general. Su De civitate Dei contiene 163 citas de autores clásicos. Sin las copias que los monjes medievales hicieron de las obras clásicas, desconoceriamos todas ellas. Hubo un respeto por el arte, y por los edificios paganos. Dejaron de utilizarse los anfiteatros y los circos, pero sólo mucho más tarde se han destrozado, en sangrientas guerras contemporáneas o en bárbaras obras de ingenie-

${ }^{5 B}$ Obra fundamental es la recientemente presentada tesis doctoral de MuNOz, Julio, E/ culto de Mithra en Hispania: caracteres especificos (tesis doctoral inédita, UNED. Madrid 1989), que recoge todas las fuentes conocidas hasta 1989 y hace un estudio en profundidad de las mismas. En esta revista aparecerá un nuevo articulo con los últimos documentos hallados en Hispania. V. asimismo el artículo de ALVAR, Jaime, "El culto de Mitra en Hispania" en Memorias de Historia Antigua, V, 1981, págs. 51-72.

58 us Las complicadas ceremonias y ritos a los que se sometía a los fieles nos impiden valorar la famosa frase de E. Renán en su Marco Aurelio, quien sostiene que "si el cristianismo hubiera sido detenido en su crecimiento por una enfermedad mortal, el mundo hubiera sido mitraísta" (citado por Vázquez Hoys en el capitulo de "Creencias religiosas". correspondiente al tomo II de la Historia General de España y América, Rialp, Madrid 1987. pág. 439.

59 "Carta a Diogneto", publicada en Padres apostólicos, Madrid, BAC, 1974, págs. 850 851. 
ría que no han sabido apreciar aquello que los primeros cristianos admiraron.

El cristianismo fue finalmente revolucionario porque constituyó una doctrina integramente orientada hacia la acción. Hubo sin duda en la Antigüedad doctrinas con juicios sobre la vida y el hombre similares en parte a los de los cristianos, pero la lección de los sabios terminaba en un rechazo de la vida. Séneca, por ejemplo, deseaba "mantenerse en reposo, a solas consigo mismo" ${ }^{\circ 0}$. Epicteto aconsejaba "no necesitar a nadie y huir de toda conciencia" ${ }^{61}$ y Marco Aurelio consideraba con nostalgia "ese retiro más apacible y más libre de cuidados que uno se crea en el fondo del alma" ${ }^{62}$. Frente a este quietismo, es digna de consideración la moral del heroísmo de los primeros cristianos ${ }^{63}$, de esos hombres a quienes les había llegado hasta la médula el cid al mundo entero y predicad el Evangelio a toda la creación» ( $M c$ 16, 15), "enseñando a todas las gentes" (Mt 28, 20). Al cabo de tres siglos el ideal cristiano vivido por una minoria (se estima que en 313 , año de la permisión del cristianismo mediante el Edicto de Milán, sólo un 10 por 100 de los ciudadanos del Imperio eran cristianos) había desmontado las categorías impuestas sobre la vida y el hombre y las habia sustituido por otras $\sin$ violencia, aunque después de haber suscitado y sufrido represiones violentísimas, quizás porque como dijo Tertuliano: "sangre de mártires, semilla de nuevos cristianos" ${ }^{64}$. Sólo mediante este espíritu pudo el cristianismo difundirse de forma que el propio Tertuliano expresara con euforia: "Somos de ayer y hemos llenado toda la tierra» 65 .

Podríamos concluir que de los dos tipos posibles de Revolución, es más duradero el ideológico que el violento, porque no son las estructuras en que el hombre se desenvuelve, sino el mismo hombre que las anima el auténtico protagonista de la Historia.

${ }^{60}$ De tranquillitate animae, $1,7$.

61 Platicas, III, 19, 8.

${ }_{62}$ Meditaciones, 55. Gredos, Madrid 1977, trad. de R. Bosch Pascual.

${ }^{63}$ Son reveladores los estudios de SHUMACHER, Heinrich, El vigor de la Iglesia primitiva, Barcelona, Herder, 1957. y Gallina, César, Los mártires de los primeros sigios, Barcelona, Lumen, 1944.

${ }^{64}$ "Semen est sanguis christianorum" (Apol. L.,13)

${ }^{65}$ Apol, XXXVII. 